\title{
What predicts the unsuccess of bariatric surgery? An observational retrospective study
}

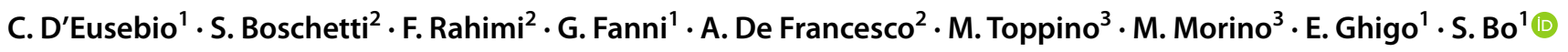

Received: 28 May 2020 / Accepted: 18 August 2020 / Published online: 25 August 2020

(c) The Author(s) 2020

\begin{abstract}
Purpose Bariatric surgery (BS) has been recognized as an effective treatment for most patients with morbid obesity, but a variable range of patients failed to achieve a successful weight-loss. Controversial data are available about predictors of unsuccess. We aimed to retrospectively assess whether clinical baseline characteristics of patients submitted to sleeve gastrectomy (SL) or gastric bypass (GBP) were associated with unsuccessful weight-loss after 12 and 24-month follow-up. Methods Three hundred patients who underwent BS from the 1st January 2016, with at least 24-months follow-up, were enrolled. Patients were divided according to their percentage of excess weight-loss (\%EWL) either $<50 \%$ or $\geq 50 \%$ after 12 and 24-month follow-up.

Results None of the patients was lost at follow-up; 56 (18.7\%) patients showed a \%EWL $<50 \%$ at 24 months. Age, neck circumference, obstructive sleep apnea (OSA) were significantly higher, while total cholesterol and \%EWL 6-months lower in those with $\% \mathrm{EWL}<50 \%$ at 12 -months. Age, neck circumference, male and OSA rates were increased, while \%EWL at 6-months lower in patients with $\% \mathrm{EWL}<50 \%$ at 24 -months. In a multiple regression model, age $(\mathrm{OR}=1.076 ; 95 \% \mathrm{CI}$ $1.029-1.125 ; p=0.001 ; \mathrm{OR}=1.066 ; 1.027-1.107 ; p<0.001)$ and $\% \mathrm{EWL}$ at 6 -months $(\mathrm{OR}=0.876 ; 0.840-0.913 ; p<0.001$; $\mathrm{OR}=0.950 ; 0.928-0.972 ; p<0.001)$ were associated with $\% \mathrm{EWL}<50 \%$ both at 12 - and 24 -months, respectively, and neck circumference $(\mathrm{OR}=1.142 ; 1.011-1.289 ; p=0.032)$ with $\% \mathrm{EWL}<50 \%$ at 24 -months.

Conclusion Older age, larger neck circumference, and \%EWL at 6-months were significantly associated with BS unsuccess, showing almost $90 \%$ of those patients an unsuccessful weight-loss early after surgery. Further larger studies with longer follow-up are needed to confirm these results.
\end{abstract}

Keywords Bariatric surgery $\cdot$ Percentage of excess weight loss $\cdot$ Predictors of weight loss $\cdot$ Retrospective observational study

\section{Introduction}

Bariatric surgery (BS) has recognized as an effective treatment for patients with morbid obesity, i.e. for those individuals with a body mass index (BMI) $\geq 40 \mathrm{~kg} / \mathrm{m}^{2}$ or a BMI $\geq 35 \mathrm{~kg} / \mathrm{m}^{2}$ with comorbidities [1]. The definition of BS success is an important issue. Different studies referred

S. Bo

simona.bo@unito.it

1 Department of Medical Sciences, University of Turin, c.so AM Dogliotti 14, 10126 Turin, Italy

2 Dietetic Unit, Città della Salute e della Scienza Hospital, Turin, Italy

3 Department of Surgical Sciences, University of Turin, Turin, Italy to the minimum weight/BMI achieved after surgery [2] and to the weight loss either as a percentage of total body weight (\% TWL) [3, 4], or as a percentage of the weight in excess (\%EWL) $[3,5]$, or as a percentage of the excess of BMI lost (\%EBMIL) [6].

Percentage of excess weight loss (\%EWL) is one of the most accepted criteria. It is calculated as the difference between baseline weight and weight after BS divided for the difference between baseline weight and the ideal weight, and it is expressed as a percentage. The $\%$ EWL cutoff $\geq 50 \%$ has been proven to be a specific and sensitive criterion for BS success [7]. The mean \%EWL values reported at 10 -years after surgery were $45.9,56.7,58.3$ and $74.1 \%$ for laparoscopic adjustable gastric banding (LAGB), gastric bypass (GBP), sleeve gastrectomy (SG) and biliopancreatic diversion, respectively [8]. 
Several baseline patient characteristics, such as increased fasting glucose levels [6, 9], lower scores of the Homeostasis Model Assessment-Insulin Resistance (HOMA-IR) index [10], and increased waist circumference values [11], have been associated with poor weight loss. Moreover, early weight loss trajectories, i.e. weight loss trends in the period immediately following BS, has been demonstrated to predict subsequent weight reduction [12]. On the other hand, associations between pre-bariatric BMI and weight loss after BS have been shown highly contrasting, since either inverse [3, $13,14]$, direct $[4,15]$ or no [16-19] relationships have been reported. Similarly, sex and age have been correlated with weight loss in some studies [4], but not in others [20] and the presence of personality disorders, psychiatric diseases, eating disorders or stressful life events (such as binge eating, sweet eating, depression, anxiety, low self-esteem, alcohol abuse, previous sexual abuse) have resulted both predictive [21] and not predictive [22] of poor BS success. Furthermore, studies presented great heterogeneity with respect to follow-up durations (from 6 months [3] to 7 years [4]), sample size (from 20 patients [18] to about 1300 [20]), type of surgery (intragastric balloon (IGB) [3], LAGB [19], GBP [6], SG [4] or biliopancreatic diversion [23]), and age and ethnic characteristics of participants [2, 4, 19].

Determining the causes of BS unsuccess is a priority to optimize access to this procedure and therefore sanitary resources. The aim of this retrospective observational study was to assess whether clinical and/or anthropometric baseline characteristics of patients who underwent GBP or SG were associated with poor \%EWL after 12 and 24-months of follow-up.

\section{Patients and methods}

This was a retrospective observational study.

We collected data from the clinical records of the first 300 patients who underwent BS at the General Surgery Department of the "Città della Salute e della Scienza" Hospital of Turin, University of Turin, from the 1st January 2016 and meeting the below-reported criteria.

Inclusion criteria were: (1) age from 18 to 65 years old; (2) BMI $\geq 35 \mathrm{~kg} / \mathrm{m}^{2}$ with comorbidities or BMI $\geq 40 \mathrm{~kg} / \mathrm{m}^{2}$, with numerous unsuccessful attempts to lose weight; (3) a minimum 2-year follow-up at our Obesity Unit. Exclusion criteria were: (1) secondary causes of obesity (e.g. hypothalamic diseases, endocrine diseases); (2) patients unable to participate in prolonged medical follow-up; (3) associated comorbidities or diseases impacting on weight loss (for example, patients who performed BS in prevision of a transplantation). Data were collected from the clinical records of all the patients, since they performed different post-BS visits (i.e. surgical, nutritionist visits).

\section{Ethical aspects}

Patients gave their informed consent to the processing of their data. The study was approved by the local Ethics Committee and was in accordance with the Declaration of Helsinki principles.

\section{Pre-operative management}

All patients first underwent a clinical examination carried out by a dietician and a MD with specific expertise in management of patients undergoing BS. During the visit, data relative to eating behaviors, previous attempts of weight loss and presence of comorbidity were collected. All patients received verbal and written dietary, exercise and behavioral recommendations. To obtain weight-loss before intervention, in order to reduce operative risks, an individually prescribed diet was given in accordance with the Mediterranean diet composition (45-55\% carbohydrates, $<10 \%$ sugars, $30 \%$ fats, $<10 \%$ saturated fats, 15-25\% proteins, 20-30 g fiber) with an energy restriction ranging from 500 to $1000 \mathrm{kcal}$ and based on the individual caloric requirements and usual intake.

The following anthropometric measurements were assessed in all patients: weight, height, waist circumference, and neck circumference. A fasting blood sample was drawn from all patients and glucose and lipid values were centrally measured.

The preoperative evaluation consisted in clinical examinations carried out by a surgeon, an anesthetist, and a psychiatrist, with expertise in the management of BS patients. All patients received information about the post-BS diet before undergoing surgery.

\section{Bariatric surgery}

In our hospital, either SG or GBP were performed. Both techniques were totally carried out by laparoscopic approach.

The type of surgery was based on the following patient features: BMI, age, gender, body fat distribution, presence of type 2 diabetes mellitus (T2DM), hiatal hernia, gastroesophageal reflux disease, patient's expectations/realistic goals, long-term treatment for a coexisting disease or condition for which absorption and pharmacokinetics of drugs are of major concern [1].

GBP is expected to have a greater effect on metabolic improvement, weight loss and maintenance with respect to SG. On the other hand, this latter is preferable to GBP for the lower surgical complexity and less frequent long-term nutritional and surgical complications [1]. 


\section{Sleeve gastrectomy}

First, a dissection by Ligasure ${ }^{\mathrm{TM}}$ of the gastrocolic ligament along the greater curve was done (from $5 \mathrm{~cm}$ proximal to pylorus up to the gastro-esophageal junction). A $32 \mathrm{~F}$ bougie was placed trans-orally until the pylorus as a guide for resection. Then, a resection of the left-lateral part of the stomach, including the complete fundus, was performed, from the antrum to the angle of His, by multiple firing of a linear cutter stapler EndoGIA (Medtronic, USA). Healing of the staple line was tested intraoperatively by methylene blue solution introduced by a nasogastric tube. The resected stomach was finally removed through a trocar site.

\section{Gastric by-pass}

GBP was performed with robotic technique (Da Vinci ${ }^{\mathrm{TM}}$ Surgical System, Intuitive, USA) in the majority of cases. A $30 \mathrm{~mL}$ gastric pouch was performed, thus separating it from the excluded stomach by a linear cutter stapler; then, an antecolic ante-gastric 150-cm Roux-en-Y limb and a $100 \mathrm{~cm}$ biliopancreatic limb were carried out in all cases. In the robotic technique, the double loop technique was adopted, with a double layer end-to-side handsewn gastro-jejunal anastomosis and mechanical or handsewn side-to-side jejuno-jejunal anastomosis, finally obtaining the Roux-en-Y limb. In the laparoscopic technique, the gastro-jejunal anastomosis was performed with a circular stapler and the jejuno-jejunal anastomosis with a linear stapler. A methylene blue test was always performed.

\section{Post-operative management}

Postoperatively, patients were advised to follow a 7-meals liquid diet during the first month after surgery, then a 5-meals soft/smooth diet was prescribed for the following four months. Starting from the sixth month onwards, foods with normal consistence were allowed and caloric sources were distributed as follows: proteins $22 \%$, lipids $28 \%$, carbohydrates $50 \%$. The caloric amount prescribed was based on the Harris-Benedict formula, considering an energy restriction ranging from 500 to $1000 \mathrm{kcal}$.

Patients were followed-up at our obesity unit at 1, 2, 6, 12 and 24 months after surgery. Daily vitamin supplementation was prescribed for the first year after surgery; thereafter, supplementation was individualized according to specific needs.

During each visit, patients were weighted, dietary habits were assessed, and the \%EWL was calculated as:

[(pre-BS weight - weight at the time of visit)/

(pre -BS weight - ideal weight)] $\times 100$.

Weight corresponding to the BMI $=25 \mathrm{~kg} / \mathrm{m}^{2}$ was considered as the ideal body weight. An unsuccessful weight loss after BS was defined as $\% \mathrm{EWL}<50 \%$, according to guidelines [1].

\section{Measurements}

Weight was measured with patient wearing light clothes and no shoes to the nearest $0.1 \mathrm{~kg}$ by a digital scale with a capacity of $300 \mathrm{~kg}$ (Wunder Sa.Bi.srl). Height was measured to the nearest $0.1 \mathrm{~cm}$ with a Stadiometer SECA 220 measuring rod (Hamburg, Germany). Waist and neck circumferences were assessed by a plastic tape meter at the umbilicus level and under the cricoid cartilage, respectively.

T2DM and arterial hypertension were diagnosed by MDs in accordance with guidelines. Obstructive sleep apnea (OSA) was hypothesized in the presence of excessive daytime sleepiness, snoring, and choking or gasping during sleep, enlarged neck circumference, and an intermediate to high risk score at the STOP-Bang questionnaire [24]. The diagnosis was confirmed by a sleep-expert neurologist by means of further exams (in-laboratory polysomnography, unattended home sleep apnea testing, etc.).

\section{Statistical analyses}

Variables are presented as mean \pm standard deviation (SD). Patients were divided according to their \%EWL either $<50$ or $\geq 50 \%$ after 12 and 24-months of follow-up.

A univariate logistic analysis was performed to test the variables associated (crude ORs) with unsuccessful weight loss at 12- and 24-months after BS (dependent variables). Then, the variables that were significantly associated with $\%$ EWL $<50$ at 12- and 24-months were inserted in a multiple logistic regression model (adjusted ORs). The Hosmer-Lemeshow test was used to evaluate the goodness-of-fit of the multivariate models.

\section{Results}

The characteristics of the participants are reported in Table 1 . The majority were women and the most common surgical procedure was sleeve gastrectomy. There was a high rate of current smokers; all patients were required to quit smoking permanently before BS. None of the patients was lost at follow-up.

In the first month after BS, mean caloric intake was $986 \pm 124 \mathrm{kcal}(21 \%$ proteins, $33 \%$ fats, $46 \%$ carbohydrates). The percentages of patients with unsuccessful weight loss, defined as $\% \mathrm{EWL}<50 \%$, progressively declined from 2 to 12 months, being $97,41,17 \%$ at 2 , 6, 12 months after BS, respectively. At 24 months, the prevalence of $\% \mathrm{EWL}<50 \%$ did not further reduce (19\%). Median (mean $\pm \mathrm{SD}$ ) values of $\% \mathrm{EWL}$ were 22.9 
Table 1 Baseline characteristics of the whole sample

\begin{tabular}{ll}
\hline Number & 300 \\
Age (years) & $44.6 \pm 10.3$ \\
Males (\%) & 10.6 \\
Smoking habits (\%) & \\
Current smokers & 57.0 \\
Past smokers & 20.3 \\
Never smoked & 22.7 \\
Job (\%) & \\
Unemployed/housewife/retired & 38.3 \\
Employee & 40.3 \\
Manual worker & 19.0 \\
Other & 2.3 \\
Sleeve gastrectomy (\%) & 77.7 \\
Gastric bypass (\%) & 22.3 \\
Pre-bariatric weight (kg) & $118.2 \pm 22.9$ \\
Height (cm) & $163.0 \pm 9.0$ \\
Pre-bariatric BMI (kg/m ${ }^{2}$ ) & $44.4 \pm 8.0$ \\
Waist circumference (cm) & $123.4 \pm 15.4$ \\
Waist-to-height ratio & $0.76 \pm 0.09$ \\
Neck circumference (cm) & $38.8 \pm 3.6$ \\
OSA (\%) & 21.7 \\
Fasting glucose (mg/dL) & $107.7 \pm 29.3$ \\
Type 2 diabetes mellitus $(\%)$ & 22.7 \\
Hypoglycemic drugs $(\%)^{\mathrm{a}}$ & 44.4 \\
Insulin (\%) & 11.1 \\
Arterial hypertension (\%) & 34.7 \\
Statins (\%) & 12.7 \\
Total cholesterol (mg/dL) & $196.5 \pm 37.8$ \\
HDL-cholesterol (mg/dL) & $47.2 \pm 13.0$ \\
Triglycerides (mg/dL) & $146.3 \pm 63.1$ \\
\hline
\end{tabular}

$B M I$ body mass index, $O S A$ obstructive sleep apnea

${ }^{a}$ Percentage of patients with type 2 diabetes treated with the drug

$(24.0 \pm 18.8), 54.4(54.8 \pm 33.0)$ and $71.2(68.9 \pm 55.1)$ at 2, 6 and 12 months, respectively. At 24 months, the prevalence of \%EWL did not further reduce, being median (mean $\pm \mathrm{SD}$ ) values of \%EWL $73.3(72.6 \pm 38.8)$.

Patients were divided according to their \%EWL (either lower or higher 50\%) at 12 months (Table 2) and at 24 months (Table 3) after surgery. Age, neck circumference, rate of OSA were significantly higher, while total cholesterol and \%EWL at 6-months lower in those with unsuccessful weight loss at 12 months. Indeed, patients with unsuccessful weight loss at 12 -months were more frequently on statins (Table 2).

Age, neck circumference, male sex, and rate of OSA were increased, while \%EWL at 6-months lower in patients with unsuccessful weight loss at 24 months. The rate of EWL $<50 \%$ was very high at 2 months in both groups (96 and $100 \%$ ), as expected, but declined at 6-months (31 and $88 \%$, in patients with successful and unsuccessful weight loss at 24 months, respectively).

Patients with successful weight loss at 24-months showed also significantly lower fasting values at 24-months of glucose $(81.7 \pm 12.8$ vs $95.9 \pm 14.7 \mathrm{mg} / \mathrm{dL}, p<0.001$; median change -20 vs $-6 \mathrm{mg} / \mathrm{dL})$, triglycerides $(83.6 \pm 35.9$ vs $124.9 \pm 64.9 \mathrm{mg} / \mathrm{dL}, p<0.001$; median change -57 vs $-16.5 \mathrm{mg} / \mathrm{dL}$ ), and higher values of HDL cholesterol $(55.8 \pm 15.1$ vs $51.1 \pm 12.5 \mathrm{mg} / \mathrm{dL}, p=0.03$; median change $+4 \mathrm{vs}+1 \mathrm{mg} / \mathrm{dL}$ ). Total cholesterol values were reduced, but the difference between patients with successful and unsuccessful weight loss at 24-months was not significant $(186.0 \pm 32.6$ vs $192.2 \pm 36.8 \mathrm{mg} / \mathrm{dL}, p=0.21$; median change $-12.5 \mathrm{vs}+4 \mathrm{mg} / \mathrm{dL}$ ). No patients discontinued statin therapy, while insulin was discontinued in all patients and hypoglycemic drugs in all except 5 patients ( 1 in the successful and 4 in the unsuccessful groups, respectively).

In a multiple regression model, age and $\% \mathrm{EWL}$ at 6 months remained significantly associated with unsuccessful weight loss both at 12 months and at 24 months, and larger neck circumference with unsuccess at 24-months (Table 4). Risk of BS unsuccess almost doubles with every decade of age $(\mathrm{OR}=1.82 ; 95 \%$ CI $1.27-2.59, p<0.001)$.

\section{Discussion}

Older age and \%EWL at 6 months were significantly associated with BS unsuccess both after 12 and 24 months, and larger neck circumference with unsuccess at 24-months after BS. Almost $90 \%$ of patients with unsuccessful weight-loss at 24 months had already showed an unsuccessful weightloss at 6 months. These results suggested that patients at risk of BS failure could be detected as early as 6 months after surgery.

The role of age in influencing post-BS weight loss is still controversial. Older age has been associated with lower weight loss at 6 months [3, 4, 11], 12 months [4, 6, 17, 19] and 24 months [4] after surgery by many, but not all studies $[9,15,16,18,20-22]$. We found a strong direct relationship between age and BS unsuccess at 24 months: the risk of unsuccess almost doubled with every increase in decade of age. Differences among studies might be due to differences in mean ages of cohorts, ranging from 34 [10] to 45 years [21], ethnicity [4, 17, 19], and employed surgical techniques. The reduced weight loss might be explained by decreased age-related resting energy expenditure (REE) due to: reduction in fat-free mass [25]; presence of adaptive thermogenic processes [26] or lower capacity to metabolize substrates [27]; the increased prevalence of comorbidity [28]; the reduction in exercise [29] and lower compliance to the received lifestyle recommendations [20]. 
Table 2 Baseline characteristics by $\%$ EWL at 12 months (left) and their association (right) with $\% \mathrm{EWL}<50 \%$ at 12 months

\begin{tabular}{|c|c|c|c|c|c|}
\hline & $\% \mathrm{EWL} \geq 50 \%$ & $\% \mathrm{EWL}<50 \%$ & OR & $95 \% \mathrm{CI}$ & $p$ \\
\hline Number & 248 & 52 & & & \\
\hline Age (years) & $43.4 \pm 10.3$ & $50.1 \pm 8.6$ & 1.076 & $1.046-1.109$ & $<0.001$ \\
\hline Males (\%) & 9.3 & 17.3 & 2.047 & $0.984-4.052$ & 0.09 \\
\hline \multicolumn{6}{|l|}{ Smoking habits (\%) } \\
\hline Current smokers & 56.9 & 57.7 & $1^{\mathrm{b}}$ & & \\
\hline Past smokers & 21.4 & 15.4 & 0.957 & $0.856-1.069$ & 0.43 \\
\hline Never smoked & 21.8 & 26.9 & 1.031 & $0.927-1.147$ & 0.58 \\
\hline \multicolumn{6}{|l|}{ Job $(\%)$} \\
\hline Unemployed/housewife/retired & 37.9 & 40.4 & $1^{\mathrm{b}}$ & & \\
\hline Employee & 40.7 & 38.5 & 0.982 & $0.892-1.082$ & 0.73 \\
\hline Manual worker & 19.8 & 15.4 & 0.959 & $0.850-1.081$ & 0.49 \\
\hline Other & 1.6 & 5.8 & 1.278 & $0.958-1.707$ & 0.10 \\
\hline SG $(\%)$ & 79.8 & 67.3 & 0.520 & $0.302-0.913$ & 0.06 \\
\hline Pre-bariatric weight (kg) & $118.9 \pm 21.8$ & $114.6 \pm 27.6$ & 0.919 & $0.979-1.003$ & 0.22 \\
\hline Height $(\mathrm{cm})$ & $163.2 \pm 8.6$ & $162.4 \pm 10.0$ & 0.991 & $0.962-1.019$ & 0.59 \\
\hline Pre-bariatric BMI $\left(\mathrm{kg} / \mathrm{m}^{2}\right)$ & $44.7 \pm 7.9$ & $43.1 \pm 8.5$ & 0.972 & $0.937-1.011$ & 0.18 \\
\hline$\%$ pre-bariatric weight loss & $-0.88 \pm 3.7$ & $-0.41 \pm 4.5$ & 1.033 & $0.954-1.118$ & 0.42 \\
\hline Waist circumference $(\mathrm{cm})$ & $123.3 \pm 14.6$ & $124.3 \pm 19.1$ & 1.010 & $0.988-1.022$ & 0.65 \\
\hline Neck circumference $(\mathrm{cm})$ & $38.6 \pm 3.4$ & $39.9 \pm 4.4$ & 1.097 & $1.027-1.171$ & 0.021 \\
\hline OSA $(\%)$ & 17.7 & 40.4 & 3.141 & $1.823-5.378$ & $<0.001$ \\
\hline Fasting glucose (mg/dL) & $107.4 \pm 28.4$ & $109.3 \pm 33.3$ & 1.002 & $0.993-1.010$ & 0.65 \\
\hline Type 2 diabetes mellitus (\%) & 23.0 & 21.2 & 0.899 & $0.474-1.622$ & 0.77 \\
\hline Hypoglycemic drugs $(\%)^{\mathrm{a}}$ & 47.4 & 54.6 & & & \\
\hline Insulin $(\%)^{\mathrm{a}}$ & 12.3 & 9.1 & & & \\
\hline Arterial hypertension (\%) & 34.7 & 34.6 & 0.997 & $0.582-1.6779$ & 0.99 \\
\hline Statins (\%) & 11.7 & 17.3 & 1.581 & $0.696-3.587$ & 0.27 \\
\hline Total cholesterol (mg/dL) & $198.9 \pm 36.9$ & $184.6 \pm 40.1$ & 0.989 & $0.981-0.998$ & 0.014 \\
\hline HDL-cholesterol (mg/dL) & $46.8 \pm 12.9$ & $49.0 \pm 13.2$ & 1.13 & $0.994-1.031$ & 0.26 \\
\hline Triglycerides (mg/dL) & $146.2 \pm 66.0$ & $146.7 \pm 47.8$ & 1.000 & $0.996-1.004$ & 0.96 \\
\hline$\%$ EWL at 6-month & $60.9 \pm 20.4$ & $25.5 \pm 57.4$ & 0.893 & $0.867-0.917$ & $<0.001$ \\
\hline
\end{tabular}

$\% E W L$ percentage excess weight loss, $S G$ sleeve gastrectomy, BMI body mass index, $O S A$ obstructive sleep apnea

a Percentage of patients with type 2 diabetes treated with the drug

${ }^{\mathrm{b}}$ Dummy variables
Among our patients, the most powerful predictor of weight loss both at 12 and 24 months was \%EWL at 6 months. Several studies investigated the relationships between early weight loss and later weight outcomes, even if the definition of satisfactory early \%EWL varies greatly. After RYGB, the EWL velocity (calculated as the difference between \%EWL at 3 and \%EWL at 1 months divided by 10 weeks) was an independent predictor for $\% \mathrm{EWL}$ at 36 months [29]. A strong correlation between \%EWL at 1 month and \%EWL at 1 year and 2 years was found [30]. Patients who lost $<30 \%$ of their initial excess weight at 6 months are unlikely to lose more than $50 \%$ at 24 months [31]. Patients in the lowest group of $\% \mathrm{EWL}$ at 1 and 3 years after BS already showed a lower mean \%EWL at 1 month [32]. A value of $\%$ EWL $>40 \%$ at 6 months after BS predicted weight loss at 2 years [33]. Patients compliance to dietary/exercise recommendations and scheduled follow-up shortly after BS was probably one of the most important factors linked to early \%EWL, as demonstrated by several researchers [34-36]. Meanwhile, individual responses to surgery due to genetic [36], hormonal [37-39] and psychosocial factors [40-42] might play an important role in determining successful weight loss after BS.

Anatomical and absorption BS-induced modifications are not the only determinant of weight loss. The gastrointestinal tract releases several polypeptide hormones acting on the hunger/satiety pattern and on energy balance. SGinduced weight loss is at least in part linked to a reduction in the release of the orexigenic ghrelin, due to the removal of the fundus and a part of the body of the stomach [37], and 
Table 3 Baseline characteristics by $\%$ EWL at 24 months (left) and their association (right) with $\% \mathrm{EWL}<50 \%$ at 24 months

\begin{tabular}{|c|c|c|c|c|c|}
\hline & $\% \mathrm{EWL} \geq 50 \%$ & $\% \mathrm{EWL}<50 \%$ & OR & $95 \% \mathrm{CI}$ & $p$ \\
\hline Number & 244 & 56 & & & \\
\hline Age (years) & $43.4 \pm 10.1$ & $49.9 \pm 9.7$ & 1.074 & $1.045-1.106$ & $<0.001$ \\
\hline Males (\%) & 8.2 & 21.4 & 3.054 & $1.557-5.860$ & 0.005 \\
\hline \multicolumn{6}{|l|}{ Smoking habits (\%) } \\
\hline Current smokers & 57.4 & 55.4 & $1^{\mathrm{b}}$ & & \\
\hline Past smokers & 20.1 & 21.4 & 1.015 & $0.906-1.139$ & 0.79 \\
\hline Never smoked & 22.5 & 23.2 & 1.010 & $0.905-1.127$ & 0.86 \\
\hline \multicolumn{6}{|l|}{ Job $(\%)$} \\
\hline Unemployed/housewife/retired & 38.1 & 39.3 & $1^{\mathrm{b}}$ & & \\
\hline Employee & 40.6 & 39.3 & 0.991 & $0.896-1.094$ & 0.85 \\
\hline Manual worker & 19.7 & 16.1 & 0.967 & $0.854-1.094$ & 0.59 \\
\hline Other & 1.6 & 5.4 & 1.268 & $0.941-1.707$ & 0.12 \\
\hline SG $(\%)$ & 77.9 & 76.8 & 0.940 & $0.535-1.714$ & 0.86 \\
\hline Pre-bariatric weight (kg) & $118.3 \pm 22.4$ & $117.8 \pm 25.4$ & 0.999 & $0.988-1.010$ & 0.89 \\
\hline Height $(\mathrm{cm})$ & $162.9 \pm 8.7$ & $163.9 \pm 9.5$ & 1.013 & $0.985-1.041$ & 0.44 \\
\hline Pre-bariatric BMI $\left(\mathrm{kg} / \mathrm{m}^{2}\right)$ & $44.6 \pm 8.1$ & $43.6 \pm 7.7$ & 0.984 & $0.951-1.015$ & 0.41 \\
\hline$\%$ pre-bariatric weight loss & $-0.78 \pm 3.9$ & $-0.87 \pm 3.5$ & 0.994 & $0.921-1.072$ & 0.88 \\
\hline Waist circumference $(\mathrm{cm})$ & $123.0 \pm 14.6$ & $125.3 \pm 18.6$ & 1.010 & $0.994-1.026$ & 0.33 \\
\hline Neck circumference $(\mathrm{cm})$ & $38.5 \pm 3.3$ & $40.4 \pm 4.4$ & 1.146 & $1.074-1.225$ & $<0.001$ \\
\hline OSA $(\%)$ & 18.9 & 33.9 & 2.210 & $1.281-3.761$ & 0.015 \\
\hline Fasting glucose (mg/dL) & $106.7 \pm 28.8$ & $112.2 \pm 31.2$ & 1.006 & $0.998-1.014$ & 0.20 \\
\hline Type 2 diabetes mellitus (\%) & 22.1 & 25.0 & 1.173 & $0.653-2.041$ & 0.64 \\
\hline Hypoglycemic drugs $(\%)^{\mathrm{a}}$ & 48.2 & 50.0 & & & \\
\hline Insulin $(\%)^{\mathrm{a}}$ & 11.1 & 14.3 & & & \\
\hline Arterial hypertension (\%) & 34.4 & 35.7 & 1.058 & $0.630-1.751$ & 0.85 \\
\hline Statins (\%) & 13.1 & 10.7 & 0.795 & $0.314-2.011$ & 0.63 \\
\hline Total cholesterol (mg/dL) & $198.3 \pm 37.7$ & $188.3 \pm 37.6$ & 0.993 & $0.986-0.999$ & 0.07 \\
\hline HDL-cholesterol (mg/dL) & $47.4 \pm 13.1$ & $46.5 \pm 12.3$ & 0.994 & $0.975-1.013$ & 0.63 \\
\hline Triglycerides (mg/dL) & $146.4 \pm 65.8$ & $145.9 \pm 50.3$ & 1.000 & $0.996-1.004$ & 0.96 \\
\hline$\%$ EWL at 6-month & $59.9 \pm 25.9$ & $32.5 \pm 48.2$ & 0.945 & $0.928-0.962$ & $<0.001$ \\
\hline
\end{tabular}

$\% E W L$ percentage excess weight loss, $S G$ sleeve gastrectomy, $B M I$ body mass index, $O S A$ obstructive sleep apnea

a Percentage of patients with type 2 diabetes treated with the drug

${ }^{\mathrm{b}}$ Dummy variables inter-individual differences in ghrelin release might account for differences in post-BS weight loss. After an early reduction in ghrelin, a late compensatory raise in ghrelin occurs in response to weight reduction following BS [43]. This finding could explain the lower weight decrease seen after SG in some cohorts [44]. GBP-induced weight-loss is linked with raised secretion of glucagon-like peptide-1 (GLP-1) and peptide YY (PYY), subsequent to the quick reaching of food bolus to distal jejunum [45] with an overall suppression of hunger [38]. Among our patients, no association between type of BS (SG or GBP) and weight loss was found. Indeed, the choice of surgical intervention was linked to the expected average impact on weight loss (higher for GBP) and the patient specific anatomical and clinical characteristics. This could have influenced the described associations.
We found an increased baseline neck circumference, a predictor of OSA and metabolic syndrome, in subjects with unsuccessful weight loss at 24 months. The association remained significant in the multivariate model, after adjusting for gender and presence of OSA, suggesting the potential of a simple and cost-saving measurement, which is less affected by the changes in the body size occurring during the course of the life. This result is intriguing, considering the emerging role of neck circumference in the prediction of major outcomes such as cardiovascular diseases and mortality $[46,47]$.

We failed to find correlations between preoperative BMI/ weight and weight loss after surgery, in line with some studies [16-19], but contrarily to others reporting a negative association between baseline BMI, waist circumference, 
Table 4 Association between baseline variables and \%EWL $<50 \%$ at 12-months (upper) and at 24-months (lower) in a multiple logistic regression model

\begin{tabular}{llll}
\hline$\%$ EWL $<50 \%$ at 12-months & OR & $95 \%$ CI & $p$ \\
\hline Age (years) & 1.076 & $1.029-1.125$ & 0.001 \\
Neck circumference (cm) & 1.039 & $0.930-1.160$ & 0.50 \\
Total cholesterol (mg/dl) & 0.993 & $0.983-1.003$ & 0.18 \\
OSA & 1.793 & $0.692-4.651$ & 0.23 \\
\%EWL at 6-month & 0.876 & $0.840-0.913$ & $<0.001$ \\
\hline \%WL <50\% at 24-months & OR & $95 \%$ CI & $p$ \\
\hline Age (years) & 1.066 & $1.027-1.107$ & $<0.001$ \\
Male sex & 1.145 & $0.329-3.989$ & 0.83 \\
Neck circumference (cm) & 1.142 & $1.011-1.289$ & 0.032 \\
OSA & 0.665 & $0.281-1.575$ & 0.35 \\
\%EWL at 6-month & 0.950 & $0.928-0.972$ & $<0.001$ \\
\hline
\end{tabular}

Goodness-of-fit by the Hosmer-Lemeshow test $p=0.99$ (for $\% \mathrm{EWL}<50$ at 12 -months), and $p=0.69$ (for \%EWL $<50$ at 24 -months)

$\% E W L$ percentage excess weight loss, OSA obstructive sleep apnea

waist-to-height ratio and post-BS weight loss at different follow-up times [3, 6, 9, 11, 15, 17, 20, 29]. Indeed, weight and BMI are both inaccurate measures of body composition with respect to fat distribution [48].

In conclusion, patients with a lower \%EWL at 6 months after surgery might be at higher risk of future unsuccess. These individuals, above all those with a larger neck circumference at baseline, might require an aggressive lifestyle intervention with more frequently scheduled followup examinations. Moreover, older patients might be worth receiving personalized indications, even by taking into account their preferences, with the aim to achieve a higher compliance.

The present study has many limitations: the short followup, the lack of socio-economic data, physical activity level, body fat measurements and hunger peptides blood concentrations. The retrospective observational design of the study does not allow to control for other confounders. The majority of our patients were women; however, the same gender distribution was reported by most published studies on patients submitted to bariatric surgery as well $[4,6,9$, 11-13, 15-17, 19-23, 29, 31, 33, 35, 36, 38, 40, 42, 48]. The number of the analyzed patients was low, but the post-hoc power analysis found that the study had a $98.5 \%$ power (with $\alpha=0.05$ ) to detect early weight-loss differences between the two groups (unsuccessful vs successful BS). We have chosen $\% \mathrm{EWL}<50 \%$ as an index of BS unsuccess. Indeed, the $\% \mathrm{EWL}<50 \%$ cutoff proved to be clinically relevant because it was able to discriminate also the metabolic response to BS in our patients, in line with literature that referred to this index to standardize outcomes of metabolic surgery $[49,50]$.

Further, larger studies with longer follow-up are needed to confirm our results in order to obtain simple prognostic factors that might improve the clinical practice by identifying individualized approaches to post-BS patients with different intensity based on the individual risk of failure.

Author contributions $\mathrm{CD}, \mathrm{SB}$ participated in the conception of the study, collection and analysis of data and interpretation of the result, manuscript writing and revision. SB participated in the conception of paper and collection of data. FR, ADF, MT, MM, EG participated in the conception of the paper, interpretation of the result, manuscript writing and revision. GF participated in the collection of data and manuscript revision.

Funding This study did not receive any funding. Open access funding provided by Università degli Studi di Torino within the CRUI-CARE Agreement.

\section{Compliance with ethical standards}

Conflict of interest The authors declare that they have no conflicts of interest.

Ethical approval The study was approved by the local Ethics Committee.

Consent to participate Informed consent was obtained from all individual participants included in the study.

Open Access This article is licensed under a Creative Commons Attribution 4.0 International License, which permits use, sharing, adaptation, distribution and reproduction in any medium or format, as long as you give appropriate credit to the original author(s) and the source, provide a link to the Creative Commons licence, and indicate if changes were made. The images or other third party material in this article are included in the article's Creative Commons licence, unless indicated otherwise in a credit line to the material. If material is not included in the article's Creative Commons licence and your intended use is not permitted by statutory regulation or exceeds the permitted use, you will 
need to obtain permission directly from the copyright holder. To view a copy of this licence, visit http://creativecommons.org/licenses/by/4.0/.

\section{References}

1. Fried M, Yumuk V, Oppert JM, Scopinaro N, Torres AJ, Weiner R, Yashkov Y, Frühbeck G, European Association for the Study of Obesity, International Federation for the Surgery of Obesity (2013) European Chapter Interdisciplinary European Guidelines on metabolic and bariatric surgery. Obes Facts 6:449-468. https ://doi.org/10.1159/000355480

2. Bastos EC, Barbosa EM, Soriano GM, dos Santos EA, Vasconcelos SM (2013) Determinants of weight regain after bariatric surgery. Arq Bras Cir Dig 26:26-32. https://doi.org/10.1590/ s0102-67202013000600007

3. Diab AF, Abdurasul EM, Diab FH (2019) The effect of age, gender, and baseline BMI on weight loss outcomes in obese patients undergoing intragastric balloon therapy. Obes Surg 29:3542-3546. https://doi.org/10.1007/s11695-019-04023-y

4. Masrur M, Bustos R, Sanchez-Johnsen L, Gonzalez-Ciccarelli L, Mangano A, Gonzalez-Heredia R, Patel R, Danielson KK, Gangemi A, Elli EF (2020) Factors associated with weight loss after metabolic surgery in a multiethnic sample of 1012 patients. Obes Surg 30:975-981. https://doi.org/10.1007/s1169 5-019-04338-w

5. Puzziferri N, Roshek TB 3rd, Mayo HG, Gallagher R, Belle SH, Livingston EH (2014) Long-term follow-up after bariatric surgery: a systematic review. JAMA 312:934-942. https://doi. org/10.1001/jama.2014.10706

6. Sans A, Bailly L, Anty R, Sielezenef I, Gugenheim J, Tran A, Gual P, Iannelli A (2017) Baseline anthropometric and metabolic parameters correlate with weight loss in women 1-year after laparoscopic Roux-En-Y gastric bypass. Obes Surg 27:2940-2949. https://doi.org/10.1007/s11695-017-2720-8

7. van de Laar AW, van Rijswijk AS, Kakar H, Bruin SC (2018) Sensitivity and specificity of $50 \%$ excess weight loss (50\%EWL) and twelve other bariatric criteria for weight loss success. Obes Surg 28:2297-2304. https://doi.org/10.1007/s11695-018-3173-4

8. O'Brien PE, Hindle A, Brennan L, Skinner S, Burton P, Smith A, Crosthwaite G, Brown W (2019) Long-term outcomes after bariatric surgery: a systematic review and meta-analysis of weight loss at 10 or more years for all bariatric procedures and a single-centre review of 20 -year outcomes after adjustable gastric banding. Obes Surg 29:3-14. https://doi.org/10.1007/s1169 5-018-3525-0

9. Faria G, Preto J, Almeida AB, Guimarães JT, Calhau C, TaveiraGomes A (2014) Fasting glycemia: a good predictor of weight loss after RYGB. Surg Obes Relat Dis 10:419-424. https://doi. org/10.1016/j.soard.2013.11.005

10. Casas-Tapia C, Araujo-Castillo RV, Saavedra-Tafur L, BertDulanto A, Piscoya A, Casas-Lucich A (2020) Higher HOMA-IR index is associated with increased excess weight loss in patients with BMI $\geq 35 \mathrm{~kg} / \mathrm{m}^{2}$ after vertical gastrectomy. Cir Esp 98:328335. https://doi.org/10.1016/j.ciresp.2019.12.002

11. Barhouch AS, Padoin AV, Casagrande DS, Chatkin R, Süssenbach SP, Pufal MA, Rossoni C, Mottin CC (2016) Predictors of excess weight loss in obese patients after gastric bypass: a 60-month follow-up. Obes Surg 26:1178-1185. https://doi.org/10.1007/ s11695-015-1911-4

12. Hindle A, de la Piedad GX, Brennan L (2017) Early post-operative psychosocial and weight predictors of later outcome in bariatric surgery: a systematic literature review. Obes Rev 18:317-334. https://doi.org/10.1111/obr.12496
13. Chen EY, McCloskey MS, Doyle P, Roehrig J, Berona J, Alverdy J, le Grange D (2009) Body mass index as a predictor of 1-year outcome in gastric bypass surgery. Obes Surg 19:1240-1242. https ://doi.org/10.1007/s11695-008-9724-3

14. Riess KP, Baker MT, Lambert PJ, Mathiason MA, Kothari SN (2008) Effect of preoperative weight loss on laparoscopic gastric bypass outcomes. Surg Obes Relat Dis 4:704-708. https://doi. org/10.1016/j.soard.2008.05.007

15. Alvarado R, Alami RS, Hsu G, Safadi BY, Sanchez BR, Morton JM, Curet MJ (2005) The impact of preoperative weight loss in patients undergoing laparoscopic Roux-en-Y gastric bypass. Obes Surg 15:1282-1286. https://doi.org/10.1381/096089205774512 429

16. Kinzl JF, Schrattenecker M, Traweger C, Mattesich M, Fiala M, Biebl W (2006) Psychosocial predictors of weight loss after bariatric surgery. Obes Surg 16:1609-1614. https://doi. org/10.1381/096089206779319301

17. Carlin AM, O'Connor EA, Genaw JA, Kawar S (2008) Preoperative weight loss is not a predictor of postoperative weight loss after laparoscopic Roux-en-Y gastric bypass. Surg Obes Relat Dis 4:481-485. https://doi.org/10.1016/j.soard.2007.09.010

18. Sarela AI, Dexter SP, O'Kane M, Menon A, McMahon MJ (2012) Long-term follow-up after laparoscopic sleeve gastrectomy: 8-9-year results. Surg Obes Relat Dis 8:679-684. https://doi. org/10.1016/j.soard.2011.06.020

19. Krimpuri RD, Yokley JM, Seeholzer EL, Horwath EL, Thomas CL, Bardaro SJ (2018) Qualifying for bariatric surgery: is preoperative weight loss a reliable predictor of postoperative weight loss? Surg Obes Relat Dis 14:60-64. https://doi.org/10.1016/j. soard.2017.07.012

20. Ansar H, Zamaninour N, Pazouki A, Kabir A (2020) Weight loss after one anastomosis gastric bypass-mini gastric bypass (OAGBMGB): patient-related perioperative predictive factors. Obes Surg 30:1316-1323. https://doi.org/10.1007/s11695-019-04270-z

21. Colles SL, Dixon JB, O'Brien PE (2008) Hunger control and regular physical activity facilitate weight loss after laparoscopic adjustable gastric banding. Obes Surg 18:833-840. https://doi. org/10.1007/s11695-007-9409-3

22. Black DW, Goldstein RB, Mason EE (2003) Psychiatric diagnosis and weight loss following gastric surgery for obesity. Obes Surg 13:746-751. https://doi.org/10.1381/096089203322509327

23. Topart P, Becouarn G, Delarue J (2017) Weight loss and nutritional outcomes 10 years after biliopancreatic diversion with duodenal switch. Obes Surg 27:1645-1650. https://doi.org/10.1007/ s11695-016-2537-x

24. Chung F, Yang Y, Liao P (2013) Predictive performance of the STOP-Bang score for identifying obstructive sleep apnea in obese patients. Obes Surg 23:2050-2057. https://doi.org/10.1007/s1169 5-013-1006-z

25. Reinders I, Visser M, Schaap L (2017) Body weight and body composition in old age and their relationship with frailty. Curr Opin Clin Nutr Metab Care 20:11-15. https://doi.org/10.1097/ MCO.0000000000000332

26. Ten Haaf T, Verreijen AM, Memelink RG, Tieland M, Weijs $P$ (2018) Reduction in energy expenditure during weight loss is higher than predicted based on fat free mass and fat mass in older adults. Clin Nutr 37:250-253. https://doi.org/10.1016/j. clnu.2016.12.014

27. Toth MJ, Tchernof A (2000) Lipid metabolism in the elderly. Eur J Clin Nutr 54:S121-S125. https://doi.org/10.1038/sj.ejcn.16010 33

28. Manini TM (2013) Mobility decline in old age: a time to intervene. Exerc Sport Sci Rev 41:2. https://doi.org/10.1097/JES.0b013 e318279fdc5

29. Mor A, Sharp L, Portenier D, Sudan R, Torquati A (2012) Weight loss at first postoperative visit predicts long-term outcome of 
Roux-en-Y gastric bypass using Duke weight loss surgery chart. Surg Obes Relat Dis 8:556-560. https://doi.org/10.1016/j.soard .2012.06.014

30. Obeidat F, Shanti H (2016) Early weight loss as a predictor of 2-year weight loss and resolution of comorbidities after sleeve gastrectomy. Obes Surg 26:1173-1177. https://doi.org/10.1007/ s11695-015-1903-4

31. Ritz P, Caiazzo R, Becouarn G, Arnalsteen L, Andrieu S, Topart P, Pattou F (2013) Early prediction of failure to lose weight after obesity surgery. Surg Obes Relat Dis 9:118-121. https://doi. org/10.1016/j.soard.2011.10.022

32. Vuolo G, Voglino C, Tirone A, Colasanto G, Gaggelli I, Ciuoli C, Ferrara F, Marrelli D (2016) Is sleeve gastrectomy a therapeutic procedure for all obese patients? Int J Surg 30:48-55. https://doi. org/10.1016/j.ijsu.2016.04.026

33. Puzziferri N, Nakonezny PA, Livingston EH, Carmody TJ, Provost DA, Rush AJ (2008) Variations of weight loss following gastric bypass and gastric band. Ann Surg 248:233-242. https://doi. org/10.1097/SLA.0b013e3181820cbc

34. Sarwer DB, Wadden TA, Moore RH, Baker AW, Gibbons LM, Raper SE, Williams NN (2008) Preoperative eating behavior, postoperative dietary adherence, and weight loss after gastric bypass surgery. Surg Obes Relat Dis 4:640-646. https://doi. org/10.1016/j.soard.2008.04.013

35. Spaniolas K, Kasten KR, Celio A, Burruss MB, Pories WJ (2016) Postoperative follow-up after bariatric surgery: effect on weight loss. Obes Surg 26:900-903. https://doi.org/10.1007/s1169 5-016-2059-6

36. Metcalf B, Rabkin RA, Rabkin JM, Metcalf LJ, Lehman-Becker LB (2005) Weight loss composition: the effects of exercise following obesity surgery as measured by bioelectrical impedance analysis. Obes Surg 15:183-186. https://doi.org/10.1381/09608 92053268381

37. Svane MS, Bojsen-Møller KN, Martinussen C, Dirksen C, Madsen JL, Reitelseder S, Holm L, Rehfeld JF, Kristiansen VB, van Hall G, Holst JJ, Madsbad S (2019) Postprandial nutrient handling and gastrointestinal hormone secretion after Roux-en-Y gastric bypass vs sleeve gastrectomy. Gastroenterology 156:1627-1641.e1. https ://doi.org/10.1053/j.gastro.2019.01.262

38. Lopez-Nava G, Negi A, Bautista-Castaño I, Rubio MA, Asokkumar R (2020) Gut and metabolic hormones changes after endoscopic sleeve gastroplasty (ESG) vs. laparoscopic sleeve gastrectomy (LSG). Obes Surg 30:2642-2651. https://doi.org/10.1007/ s11695-020-04541-0

39. Cornejo-Pareja I, Clemente-Postigo M, Tinahones FJ (2019) Metabolic and endocrine consequences of bariatric surgery. Front Endocrinol (Lausanne) 10:626. https://doi.org/10.3389/fendo .2019 .00626

40. Khorgami Z, Arheart KL, Zhang C, Messiah SE, de la CruzMuñoz N (2015) Effect of ethnicity on weight loss after bariatric surgery. Obes Surg 25:769-776. https://doi.org/10.1007/s1169 5-014-1474-9
41. Sheets CS, Peat CM, Berg KC, White EK, Bocchieri-Ricciardi L, Chen EY, Mitchell JE (2015) Post-operative psychosocial predictors of outcome in bariatric surgery. Obes Surg 25:330-345. https ://doi.org/10.1007/s11695-014-1490-9

42. Hecht LM, Pester B, Braciszewski JM, Graham AE, Mayer K, Martens K, Hamann A, Carlin AM, Miller-Matero LR (2020) Socioeconomic and racial disparities in bariatric surgery. Obes Surg 30:2445-2449. https://doi.org/10.1007/s11695-020-04394-7

43. Cummings DE, Weigle DS, Frayo RS, Breen PA, Ma MK, Dellinger EP, Purnell JQ (2002) Plasma ghrelin levels after dietinduced weight loss or gastric bypass surgery. N Eng J Med 346:1623-1630. https://doi.org/10.1056/NEJMoa012908

44. Ademi Z, Tomonaga Y, van Stiphout J, Glinz D, Gloy V, Raatz H, Bucher HC, Schwenkglenks M (2018) Adaptation of cost-effectiveness analyses to a single country: the case of bariatric surgery for obesity and overweight. Swiss Med Wkly 148:w14626. https ://doi.org/10.4414/smw.2018.14626

45. Jirapinyo P, Jin DX, Qazi T, Mishra N, Thompson CC (2018) A meta-analysis of GLP-1 after Roux-En-Y gastric bypass: impact of surgical technique and measurement strategy. Obes Surg 28:615626. https://doi.org/10.1007/s11695-017-2913-1

46. Caro P, Guerra X, Canals A, Weisstaub G, Sandaña C (2019) Is neck circumference an appropriate tool to predict cardiovascular risk in clinical practice? A cross-sectional study in Chilean population. BMJ Open 9:e028305. https://doi.org/10.1136/bmjop en-2018-028305

47. Zhang J, Guo Q, Peng L, Li J, Gao Y, Yan B, Fang B, Wang $\mathrm{G}$ (2018) The association of neck circumference with incident congestive heart failure and coronary heart disease mortality in a community-based population with or without sleep-disordered breathing. BMC Cardiovasc Disord 18:108. https://doi. org/10.1186/s12872-018-0846-9

48. Eriksson Hogling D, Rydén M, Bäckdahl J, Thorell A, Arner P, Andersson DP (2018) Body fat mass and distribution as predictors of metabolic outcome and weight loss after Roux-en-Y gastric bypass. Surg Obes Relat Dis 14:936-942. https://doi. org/10.1016/j.soard.2018.03.012

49. Michalik M, Bobowicz M, Buchwald H (2015) A numerical scale to assess the outcomes of metabolic/bariatric surgery (NOMS). Wideochir Inne Tech Maloinwazyjne 10:359-362. https://doi. org/10.5114/wiitm.2015.54085

50. Bhandari M, Fobi M, Buchwald JN, Bariatric Metabolic Surgery Standardization (BMSS) Working Group (2019) Standardization of bariatric metabolic procedures: World Consensus Meeting Statement. Obes Surg 29:309-345. https://doi.org/10.1007/s1169 5-019-04032-x

Publisher's Note Springer Nature remains neutral with regard to jurisdictional claims in published maps and institutional affiliations. 